\title{
Parasitic associations of a threatened Sri Lankan rainforest rodent, Mus mayori pococki (Rodentia: Muridae)
}

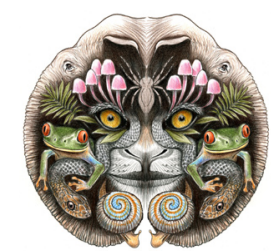

\author{
Pamoda B. Ratnaweera1, Mayuri R. Wijesinghe² \& Preethi V. Udagama-Randeniya ${ }^{3}$ \\ 1,2,3 Department of Zoology, University of Colombo, Cumaratunga Munidasa Mawatha, Colombo 03, Sri Lanka. \\ ${ }^{1}$ (Current affiliation: Science and Technology Degree Programme, Uva Wellassa University, Badulla, Sri Lanka) \\ Email: ${ }^{1}$ pamoda_b2@yahoo.com; ${ }^{2}$ mayrui@zoology.cmb.ac.lk; ${ }^{3}$ dappvr@yahoo.com (corresponding author)
}

\begin{abstract}
Parasitic investigations of the subspecies Mus mayori pococki were carried out in four rainforests that included two man and biosphere reserves and two forest reserves of Sri Lanka from October 2006 to August 2007. Rodents were live-trapped using Shermans traps. Of the 117 individuals of M. m. pococki captured 73\% were infested with four types of ectoparasites mites of the genus Echinolaelaps, a louse Polyplax serrata, a larval stage of hard tick Ixodes and pseudoscorpions of the genus Megachernes. Mites were the most abundant ectoparasite of this rodent host. Faecal examination revealed the presence of a nematode larva of the Order Strongylida and five types of parasitic ova; three nematode ova types i.e. strongyle, strongyloides, ascarid types, and cestode and mite ova. In comparison to the non-infested hosts, those infested did not show a significant difference in body weight and size. Both sexes had an equal probability of being exposed to ectoparasites. The present study on the parasitic investigations of $M$. $m$. pococki reports four new host-ectoparasite and six new endoparasitic records for the Sri Lankan rodent host.
\end{abstract}

Keywords: Ectoparasites, intestinal parasites, Mus mayori pococki, rainforests, Sri Lanka.

Date of publication (online): 26 June 2010 Date of publication (print): 26 June 2010 ISSN 0974-7907 (online) | 0974-7893 (print)

Editor: Anjum N. Rizvi

\section{Manuscript details:}

Ms \# 02194

Received 04 May 2009

Final revised received 28 May 2010

Finally accepted 29 May 2010

Citation: Ratnaweera, P.B. M.R. Wijesinghe \& P.V. Udagama-Randeniya (2010). Parasitic associations of a threatened Sri Lankan rainforest rodent, Mus mayori pocock (Rodentia: Muridae). Journal of Threatened Taxa 2(6): 901-907.

Copyright: () Pamoda B. Ratnaweera, Mayuri R. Wijesinghe \& Preethi V. UdagamaRandeniya 2010. Creative Commons Attribution 3.0 Unported License. JoTT allows unrestricted use of this article in any medium for non-profit purposes, reproduction and distribution by providing adequate credit to the authors and the source of publication.

Author Details, Author Contribution, Acknowledgements: See end of this article.
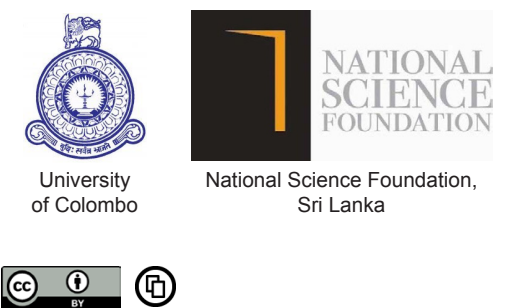

OPEN ACCESS | FREE DOWNLOAD

\section{INTRODUCTION}

Wild animals harbour parasites that in addition to having direct deleterious effects on their hosts also transmit pathogens (Bechara et al. 1998; Pietzsch et al. 2005). Both parasites and pathogens affect host physiology, often leading to disease conditions that could result in host mortality (Bolen \& Robinson 1999). Parasitic infections may also increase vulnerability to predation through alteration of host behaviour (Mech 1966; Moore 1983). Thus, parasitic infections can directly and indirectly lead to disruptions in ecological relationships within communities and contribute to population decline of endangered species (Durrer \& Schmid-Hempel 1995; Krasnov et al. 2005). It follows that research and knowledge of wildlife diseases are important for wildlife conservation and management (Bolen \& Robinson 1999).

Ecologically, murids have a significant beneficial impact on the environment as seed predators and dispersers, as insectivores and as important prey species of reptiles, birds and mammals (Kern 1981). In the face of rapid deforestation, they face threats of extinction due to habitat loss. Mus mayori is an endemic rodent restricted to the southwestern rainforests of Sri Lanka. It belongs to the subgenus Coelomys and is represented by two subspecies: $M$. mayori mayori confined to the montane zone and $M$. mayori pococki the low country wet zone (Phillips 1980). M. mayori has been currently listed as a Vulnerable species (Goonatilake et al. 2008). Parasitic associations of $M$. mayorihave been poorly investigated. Previous records of Turk (1950), Phillips (1980) and Crusz (1984) reported the presence of only two ectoparasites, a mite, Laelaps atypicus and a flea, Stivalius phoberus, and two intestinal parasites, a digenean trematode, Brachylaemus advena and a cestode of the genus Hymenolepis, associated with this rodent species.

The objective of this study was to extensively investigate the parasites of M. mayori. The present study reports ectoparasites and intestinal parasites of $M$. m. pococki mainly from two man and biosphere reserves, Kanneliya and Sinharaja, and two other forest reserves, Yagirala and Walankanda in the wet zone of Sri Lanka. Concurrently, the incidence of ectoparasite infestations, sex ratios of infected and non infected individuals, and the effect of body 
dimensions on parasitic infestations are also discussed. Such studies may also provide baseline data on parasitic associations of threatened endemic rodents that would be useful in conserving this species in the wild.

\section{MATERIALS AND METHODS}

\section{Study sites}

The four sites selected for the present study are located in the southwest wet zone of Sri Lanka and constitute the typical wet evergreen forest type (de Rosayro 1959). The two forests Kanneliya and Sinharaja which were surveyed extensively are two of the largest and relatively undisturbed rainforests remaining in the island. The other two forests Yagirala and Walankanda were sparsely surveyed. Although similar in vegetation, these two forests are much smaller in extent and are relatively disturbed ecosystems.

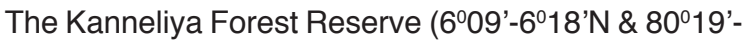
$80^{\circ} 27^{\prime} \mathrm{E}$ ) is an integral component of a forest complex located in the southwest low country of Sri Lanka. The average annual rainfall exceeds $4000 \mathrm{~mm}$, which is mainly from the southwest monsoon. The relatively drier periods are from January to March and the mean monthly temperature is around $27^{\circ} \mathrm{C}$. Kanneliya, which has an area of 6143 ha and an elevation of about $300 \mathrm{~m}$, is ranked among the most important natural forests in the Southern Province for the protection of head waters of river systems (IUCN \& Forest Department 1996). Based on the rich faunal and floral diversity the country's rainforests are considered as a biodiversity hotspot (Myers et al. 2000). Its protection was strengthened after this forest was declared a Man and Biosphere Reserve in 2004 (UNESCO 2008).

The Sinharaja forest is also located in the wet zone in South-West Sri Lanka (6021'-6 $\left.6^{\circ} 26^{\prime} \mathrm{N} \& 8^{\circ} 21^{\prime}-80^{\circ} 34^{\prime} \mathrm{E}\right)$. This forest covers an area of 11000 ha and has an elevation of about $640 \mathrm{~m}$. The annual rainfall ranges from $3750-5000$ $\mathrm{mm}$ and the mean monthly temperature ranges from 18-27 ${ }^{\circ} \mathrm{C}$. Much of the precipitation comes during the periods of the southwest monsoon and the northeast monsoon. It is of special interest as it represents a biome that dates back in its evolutionary history to Gondwanaland and is rich in biodiversity and endemism. The forest was designated a Biosphere Reserve under UNESCO's Global Network of Biosphere Reserves. Subsequently, UNESCO declared it a Natural World Heritage Site (Wijesinghe \& Brooke 2005).

The Yagirala $\left(6^{0} 21^{\prime}-6^{0} 26^{\prime} \mathrm{N} \& 80^{\circ} 06^{\prime}-80^{\circ} 11^{\prime} \mathrm{E}\right)$ Forest Reserve is a rainforest patch much smaller in size covering an area of about 2000ha. The forest has an elevation of about $134 \mathrm{~m}$ and receives a rainfall of $4000 \mathrm{~mm}$ per year. The temperature ranges from $27-28.5^{\circ} \mathrm{C}$. The forest is exposed to human disturbance as its located in close proximity to the main road and human settlements.
The Walankanda Forest Reserve $\left(6^{\circ} 29^{\prime} \mathrm{N} \& 80^{\circ} 28^{\prime} \mathrm{E}\right)$ is a very small patch of rainforest with an area of about $940 \mathrm{ha}$ and an elevation of about 560m. Unlike Kanneliya and Sinharaja, both these forests are exposed to human disturbance.

\section{Host}

M. $m$. pococki is a medium-sized mouse with a body length (snout end to anus) of around $90 \mathrm{~mm}$. Its tail is slender, scaly and about the same length as the head and body. Feet are comparatively large; ears are moderately large, rounded and naked. The general colour of the upper part of the body is fulvous brown. This species is easily recognized by its flattened spiny fur of the dorsal area and the pure white under parts (Phillips 1980).

\section{Trapping procedure}

The live trapping survey of $M$. $m$. pococki was conducted in Kanneliya from October 2006 to February 2007, and from June to August 2007 in Sinharaja, Yagirala, and Walankanda forests. Animals were captured using Shermans traps, baited with mildly roasted coconut kernel. Traps were laid in the evening and checked the next morning. The captured animals were removed into handling bags, weighed, measured sexed and released after the parasitic survey.

A total of 117 individuals of $M . m$. pococki captured from the four different forest reserves (Kanneliya [ $N=99]$, Sinharaja [ $\mathrm{N}=11]$, Yagirala $[\mathrm{N}=4]$ and Walankanda [ $=$ 3]) were screened for ectoparasites. Faecal samples of 12 animals from Kanneliya and three from Walankanda were examined for intestinal parasites.

\section{Ectoparasites}

Body, paws and ears of each captured individual of $M$. m. pococki were examined for the presence of Ectoparasites (Whitaker 1988). Fur was combed with a fine brush to collect the ectoparasites. The parasites were picked using fine forceps, fixed in $70 \%$ alcohol, and mounted using a modification of the procedures described by Whitaker (1988). Mounted specimens were observed under light microscopy (Nikon, Japan). Parasite load were categorized and ranked as (i) Low if less than five were detected after a fine search, (ii) Moderate if 5-15 parasites were observed when combing the fur, (iii) High if more than 15 parasites were observed during combing.

Ectoparasites were provisionally identified based on several descriptions and available keys. Keys by Strandtmann \& Mitchell (1963) were used for the identification of the mite, which was confirmed by Dr. Ashley Dowling, Emeritus Professor of Biology, University of Kentucky, USA. Identification of the louse (Ignoffo 1959) was authenticated by Dr. Lance Durden, Assistant Professor of Biology, University of Southern Georgia, USA. Ticks were identified using available keys (Seneviratna 1965). Pseudoscorpions were identified by 
Dr. Mark Harvey, Senior Curator and Head, Department of Terrestrial Zoology, Western Australian Museum, Australia.

Incidence of parasitized hosts i.e. the percentage of hosts infected with ectoparasites (Gannon \& Willing 1995) was also determined.

\section{Intestinal parasites}

To examine intestinal parasites, fresh faecal samples collected from handling bags and those ejected while handling animals were collected into glass vials containing $10 \%$ formalin. A thin faecal smear was prepared on a drop of saline and iodine separately and was observed under light microscopy (Kilingenberg 1993). The prepared smears were screened for parasitic ova and larvae, which were identified using the WHO (1994) Bench Aids.

\section{Statistical analysis}

Epilnfo Version 6 (USA \& World Health Organization, Switzerland) computer software package was used for analysis of data. Chi squared test was used to compare the incidence of parasitized hosts in different forest reserves as well as to compare the gender of hosts with ectoparasite infestations. To investigate the effects of parasites on the weight reduction and size retardation of infested hosts, a pairwise t-test was performed using mean body lengths and weights of infected and noninfected individuals in each forest. The $p$ value was set at 0.05 .

\section{RESULTS}

\section{Ectoparasites}

Four types of ectoparasites were found to be associated with $M . m$. pococki: mites, a louse, a larval stage of a tick and pseudoscorpions. Mites were identified to the generic level only and found to belong to the genus Echinolaelaps. The louse species was identified as Polyplax serrata. The ticks found on M. mayori from Kanneliya and Sinharaja were identified as larval stages of the hard tick, Ixodes. A number of pseudoscorpions were found to belong to the genus Megachernes (Pseudoscorpiones: Chernetidae).

All four parasites were recorded from Kanneliya. Mites and the tick were recorded from Sinharaja, while only the mites were found from the other two forest patches. All ectoparasites encountered in this study were first time records for M. m. pococki in Sri Lanka.

\section{Intestinal parasites}

Examination of faecal matter revealed the presence of three nematode egg types (Strongyle type, Strongyloides type, Ascarid type), cestode eggs, mite eggs and a nematode larva of order Strongylida from M. m. pococki (Image 1). All egg types and nematode larvae were recorded from Kanneliya while the hosts collected from
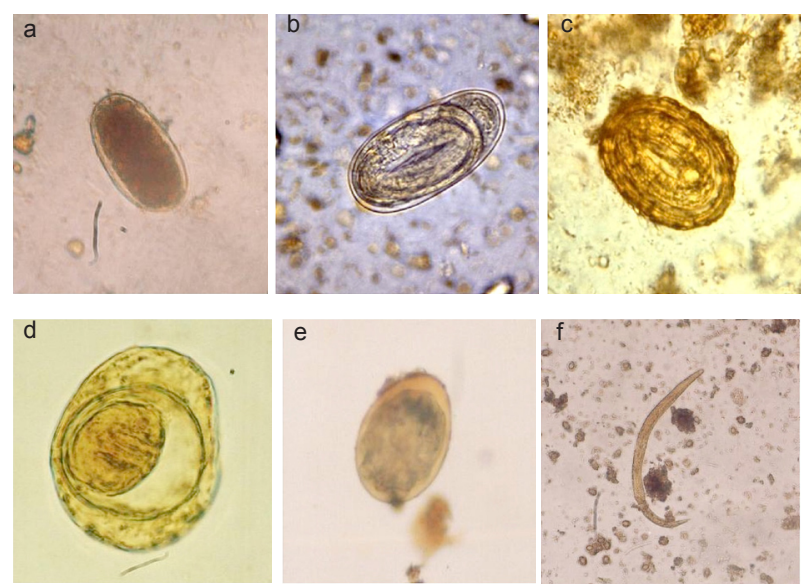

Image 1. Photomicrographs of the intestinal parasitic eggs $\&$ the larva detected in faecal samples of Mus mayori. a - strongyle type egg ( $x 400)$; b - strongyloides type egg ( $x 800)$; c - ascarid type egg (x800); $d$ - cestode egg (x800); e - mite egg (x200); $\mathrm{f}$ - nematode larva (order Strongylida) (x200)

Walankanda appeared to be free of intestinal parasites. All these intestinal parasitic associations are novel records for endemic M. m. pococki in Sri Lanka.

\section{Host-parasite parameters}

$73 \%$ of individuals examined were infested with ectoparasites $(\mathrm{N}=117)$. The incidence of parasitized hosts was $76 \%, 64 \%, 50 \%$ and $33 \%$ from Kanneliya $(N=75)$, Sinharaja (7), Yagirala (2) and Walankanda (1), respectively. No significant difference in incidence was observed collectively in the two man and biosphere reserves compared to that of the two forest patches $\left(X^{2}=\right.$ $0.07, \mathrm{p}>0.05)$.

The mite, Echinolaelaps species, predominated the ectoparasites where $100 \%$ incidence was observed from Kanneliya (Table 1). About four lice were found from three individuals of hosts from Kanneliya. Two larvae of Ixodes ticks were found one each from Kanneliya and Sinharaja. Approximately ten psuedoscorpions including juveniles and adults were found predating on one individual of $M . m$. pococki from Kanneliya. Mites were the only ectoparasites found on M. m. pococki from Yagirala and Walankanda, while both mites and ticks were found on those from Sinharaja (Table 1).

Of the infected animals captured from Kanneliya, 24\% ( $N=18$ ) showed a High infestation load, while $24 \%$ ( $N=$ 18) had a Medium load and $52 \%(\mathrm{~N}=39)$ showed Low infestations (Table 1). Three infected hosts each from Sinharaja carried Low and High parasite loads while one manifesteded Medium parasite load. Although the number of hosts captured from Yagirala and Walankanda forest reserves was Low, those that were infested with ectoparasites carried High parasite loads (Table 1).

Mites were found on the dorsal and ventral parts of the body, close to the skin of $M$. m. pococki as well as freely moving over the fur, while lice were firmly attached 
Table 1. Incidence of parasitized M. m. pococki infested with ectoparasites in the four forest reserves.

\begin{tabular}{|c|c|c|c|c|c|c|c|c|c|}
\hline \multirow{3}{*}{ Forest reserve ${ }^{a}$} & \multicolumn{5}{|c|}{ Host } & \multicolumn{4}{|c|}{ Ectoparasites } \\
\hline & \multirow[b]{2}{*}{$\mathrm{N}^{\mathrm{b}}$} & \multirow[b]{2}{*}{$\begin{array}{l}\text { Incidence } \\
(\%)\end{array}$} & \multicolumn{3}{|c|}{$\begin{array}{l}\% \text { of parasitized hosts } \\
\text { with different } \\
\text { ecotparasite loads }\end{array}$} & $\begin{array}{l}\text { Echinolaelaps } \\
\text { mites }\end{array}$ & $\begin{array}{l}\text { P. serrata } \\
\text { louse }\end{array}$ & $\begin{array}{l}\text { Ixodes } \\
\text { tick larvae }\end{array}$ & $\begin{array}{l}\text { Megachernes } \\
\text { Pseudoscorpions }\end{array}$ \\
\hline & & & 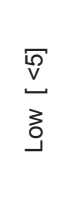 & 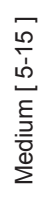 & 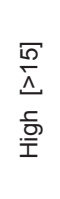 & $\mathrm{N}(\%)$ & $\mathrm{N}(\%)$ & $\mathrm{N}(\%)$ & $\mathrm{N}(\%)$ \\
\hline Kanneliya & 99 & $76(\mathrm{~N}=75)$ & 52 & 24 & 24 & $75(100)$ & $3(4)$ & $1(1)$ & $1(1)$ \\
\hline Sinharaja & 11 & $64(\mathrm{~N}=7)$ & 43 & 14 & 43 & $7(100)$ & - & $1(1)$ & - \\
\hline Yagirala & 4 & $50(\mathrm{~N}=2)$ & - & - & 100 & $2(100)$ & - & - & - \\
\hline Walankanda & 3 & $33(\mathrm{~N}=1)$ & - & - & 100 & $1(100)$ & - & - & - \\
\hline
\end{tabular}

a - Kanneliya and Sinharaja - Man and Biosphere Reserves; Yagirala and Walankanda - forest patches; ${ }^{b}$ - Number of hosts observed; ${ }^{\circ}$ - \% of infested individuals; ${ }^{\mathrm{d}}$ - $\%$ of parasitized hosts with different ectoparasite loads per individual

Table 2. Mean body length and weight of the ectoparasite-infested and non-infested individuals of $M$. m. pococki captured from the four forest reserves

\begin{tabular}{|c|c|c|c|c|c|}
\hline \multirow{2}{*}{ Forest reserve $^{\mathrm{a}}$} & \multirow{2}{*}{$\mathrm{N}^{\mathrm{b}}$} & \multicolumn{2}{|c|}{ Mean body length (mm) } & \multicolumn{2}{c|}{ Mean weight (g) } \\
\cline { 3 - 6 } & & Infested & Non-infested & Infested & Non-infested \\
\hline Kanneliya & 99 & 90.6 & 97.0 & 38.3 & 38.0 \\
\hline Sinharaja & 11 & 91.8 & 86.0 & 40.5 & 41.0 \\
\hline Yagirala & 4 & 90.5 & - & 51.2 & 55.0 \\
\hline Walankanda & 3 & 82.5 & 80.0 & 25.0 & 25.0 \\
\hline
\end{tabular}

a - Kanneliya and Sinharaja - Man and Biosphere Reserves; Yagirala and Walankanda - forest patches;

b - Number of hosts observed. According to the Paired T-Test, there was no significant difference in weight $(T=-0.94)$ and body length $(T=0.17)$ between infected and non infected individuals

to the skin of the dorsal surface of the animals. Ticks were found attached to the inner surface of the ear lobe, while the pseudoscorpions were on the dorsal side of the hosts.

The ectoparasite infestations did not significantly affect either the body weight or the length of the hosts (Paired T-Test : Weight T $=-0.94, p>0.05$; Body length $T$ $=0.17, p>0.05)$ (Table 2). A similar proportion of males and females (50.6\% males, $49.4 \%$ females) were infected with ectoparasites $\left(X^{2}=0.02, p>0.05\right)$.

\section{DISCUSSION}

Information on parasitic associations of wild rodents, particularly those inhabiting rainforests, is scarce. In Sri Lanka apart from three preliminary studies (Turk 1950; Phillips 1980; Crusz 1984), the last conducted approximately 25 years ago, no recent investigations are reported on M. mayori. Crusz (1984) specified his finding to the subspecies M. m. mayori, and Turk (1950) and Phillips (1980) to the species M. mayori. Thus both the ectoparasites and intestinal parasites reported in the present study form the first records for endemic threatened M. m. pococki of Sri Lanka. Although there seems to be no adverse effects from these parasites on $M$. m. pococki in Sri Lanka, it has been reported that sucking lice are responsible for transmitting louse borne typhus in Japan (Shinozaki et al. 2004) and may be intramurid vectors of murine typhus and other zoonoses (Durden \& Page 2008).

All mites found during the present study are of the genus Echinolaelaps. They are common all over the world and are also reported found from southeast Asia (Strandtmann \& Mitchell 1963). This mite genus was previously recorded from the Spiny Rat $M$. mayori, Common House Rat Rattus rattus kandianus and Long-tailed Tree Mouse Vandeleuria spp. in Sri Lanka (Turk 1950). Several species of Echinolaelaps were recorded from New Guinea, Borneo, Thailand, Vietnam 
and Indonesia (Strandtmann \& Mitchell 1963; Durden \& Page 2008) from Rattus spp. and several other murids. Echinolaelaps is reported to be a vector of Hepatozoon spp., the protozoan blood parasites which infect rats, and also suspected to be a vector of murine typhus because of its abundance on the reservoir host (Jakeman 1961).

The two Ixodes ticks found on M. m. pococki during the current investigation could not be further identified, as both specimens were larval stages. Genus Ixodes is uncommon in Sri Lanka and is represented by only two species, I. petauristae, recorded from Petaurista philippensis lanka (The Grey Flying Squirrel) and I. ceylonensis recorded from both $R$. r. kandianus (Common House Rat) and from Herpestes lanka (Grey or Silvery Mongoose) (Seneviratna 1965). The ticks recorded in the present study form a new host-parasite record from Sri Lanka. Although Ixodes ticks in Sri Lanka have low medical and veterinary significance, Ixodes species in other countries are responsible for transmission of Lyme disease and other zoonotic diseases (Spielman et al. 1985; Cotte et al. 2008). I. granulaus from Malaya transmit a virus causing Russian Spring Summer Encephalitis (Seneviratna 1965). Kurtenbach et al. (1995) reported that infestation of rodents with larval $I$. ricinus is an important factor in the transmission cycle of Borrelia burgdorferi in German woodlands. As suggested by Seneviratna (1965), it may be plausible that this Ixodes tick species was introduced to Sri Lanka from other countries through migrant birds, as the island is a destination for a huge number of migrant bird species from all over the world. Ixodus ticks are known to occur in areas where there is high rainfall and dense vegetation (Gray 2001) which conforms to the two rainforests of the present study.

Eight species of pseudoscorpions of the family Chernetidae are recorded from Sri Lanka (Harvey 2008). The pseudoscorpions of genus Megachernes detected in the current study form a new record for Sri Lanka. Pseudoscorpions are known to feed on insects and mites (Verma 2002), making it likely that the pseudoscorpions found in the present study were preying upon the mites found on $M$. m. pococki. Most M. m. pococki individuals harboured the mite of the genus Echinolaelaps (100\% incidence from all infested hosts). Thus, it may be inferred that the environmental conditions of the forest offers optimal conditions for the survival of mites.

The low species diversity and inflated densities spontaneously lead to the concept of 'density compensation" (MacArthur et al. 1972). Species of ectoparasites are likely to compete for resources. In the absence of some competitors the remaining species may respond by increased densities, or a change in the use of space (Bengtson et al. 1986). This may be a plausible reason for a fewer number of $M$. $m$. pococki caught from the forest patches at Yagirala and Walankanda, to harbour high parasitic infestations. Although no disease conditions were detected in them, it would be important to ascertain if the low abundance of $M . m$. pococki in those forests is linked to high parasite loads. Since these two forests are small and isolated forest patches in contrast to Kanneliya and Sinharaja, it would be interesting to examine if the higher parasite loads are a result of the greater anthropogenic disturbances.

Pathogens transmitted by ectoparasites cause diseases that alter the physiology and behaviour of the host. These can be manifested through their feeding and mobility, resulting in weight loss and reduced growth (Jog \& Watve 2005). Heavier animals are infected more significantly by parasites than lighter ones (Waweru \& Odanga 2004). However, in the present study individuals with high load of infestation were similar in body weight and size to the non-infected individuals and both sexes have an equal probability to be infested by ectoparasites. Only $27 \%$ of hosts were found to be free of ectoparasites in this study. The reason could be that the parasites were not colonized by chance (Krasnov et al. 2006).

Helminths are cosmopolitan and play a significant role in the morbidity and mortality of people and animals in many parts of the world. Most prevalent are the intestinal helminths and these infections are often diagnosed by observing ova and/or juvenile nematodes faecal samples. Helminths also have the potential to regulate the abundance of the host populations (Scott \& Lewis 2008). It is not possible to identify parasite ova to the species level unless adult parasites are observed. Such an examination within the context of the present study will necessitate the sacrificing of wild rodents which is not desirable for endangered populations which are currently facing threat.

Although the present study was only an off-shoot of an ecological investigation of rodents, it is the first study that reveals levels of parasitic infestations in wild rodents in Sri Lanka. It is unfortunate that some of the parasites were not identified to the species level because some distinguishing structures were not clear in the processed specimens. The present survey records high ectoparasite infestations in Kanneliya. Fewer numbers of ectoparasites from Sinharaja, Yagirala and Walankanda may be ascribed to small numbers of host specimens investigated. This study is significant as it revealed parasitic associations of the wild dwelling threatened endemic murid rodent M. m. pococki. Small populations that are prone to parasitic infections can easily be wiped out from their habitats; hence parasite surveys are important for the conservation of wildlife populations. Wild animals harbouring parasites can also spread diseases to humans. Despite the limitations encountered, investigations of this nature, providing information on parasitic associations of native rodents are vital in order to assess the magnitude of the impact of these parasites on wildlife populations as well as to ascertain the potential health risks to humans. 'Conservation Medicine' conceptualizes that future disasters with regards to parasitic infestations may 
be averted by integrating our knowledge of parasites, pathogens and host physiology with that of ecology and society so as to begin to evolve towards a more mature relationship with living nature (Soule 2002).

This is the first parasitic investigation conducted on wild murids, and more importantly on a threatened endemic rodent, in rainforests in Sri Lanka. Such studies will provide baseline data that would be useful in conserving these species in the wild.

\section{REFERENCES}

Bechara, G.H., M.P.J. Szabo, J.M.B. Duarte, E.R. Matushima, M.C. Pereira, Y. Rechav, J.E. Keirans \& L.J. Fielden (1998). Ticks associated with wild animals in the Nhecolandia Pantanal, Brazil. Annals of the New York Academy of Sciences 916: 289-297.

Bengtson, S.A., G. Brinck-Lindroth, L. Lundqvist, A. Nilsson \& S. Rundgren (1986). Ectoparasites on small mammals in Iceland: Origin and population characteristics of a speciespoor insular community. Holarctic Ecology 9: 143-148.

Bolen, E.G. \& W.L. Robinson (1999). Wildlife diseases, pp.113 141. In: Wildlife Ecology and Management, $4^{\text {th }}$ Edition. Prentice-Hall, Upper Saddle River, New Jersey, USA, xiv+605pp.

Cotte, V., S. Bonnet, D. Le Rhun, E. Le Naour, A. Chauvin, H.J. Boulouis, B. Lecuelle, T. Lilin \& M. Vayssier-Taussat (2008). Transmission of Bartonella henselae by Ixodes ricinus. Emerging infectious diseases. Health care industry CNET Networks, Inc., a CBS Company.

Crusz, H. (1984). Parasites of endemic and relict vertebrates: a biogeographical review, pp.321-351. In: Fernando, C.H. (ed.). Ecology and Biogeography in Sri Lanka. Dr. W. Junk Publishers, The Hague, Boston, $x i x+505 p p$.

De Rosayro, R.A. (1959). The application of aerial photography to stock mapping and inventories on an ecological basis in rainforests in Ceylon. Empire Forestry Review 38: 141-174.

Durden, L.A. \& B.F. Page (2008). Ectoparasites of commensal rodents in Sulawesi Utara, Indonesia, with notes on species of medical importance. Medical and Veterinary Entomology 5: $1-7$.

Durrer, S. \& P. Schmid-Hempel (1995). Parasites and the regional distribution of bumblebee species. Ecography 18: 114-122.

Gannon, M.R. \& M.R. Willing (1995). Ecology of ecto-parasites from tropical bats. Environmental Entomology 24(6): 14951503.

Gray, G.S. (2001). The biology of lxodes ticks, with special reference to Ixodes ricinus. In: Proceedings of the symposium Current Research on Tick-Borne Infections. Kalmar, Sweden.

Goonatilake, W.I.L.D.P.T.S. de A., P.O. Nameer, S. \& Molur (2008). Mus mayori. In: IUCN 2010. IUCN Red List of Threatened Species. Version 2010.1. <www.iucnredlist.org>. Downloaded on 11 June 2010

Harvey, M.S. (2008). Pseudoscorpions of the World. Western Australian Museum, Perth. <http://www.museum.wa.gov.au/ arachnids/pseudoscorpions/>. On-line version 1.1. dated 27 December 2008.

Ignoffo, C.M. (1959). Key and notes to the Anoplura of Minnesota, American Midland Naturalist 61: 470-479.

IUCN \& Forest Department (1996). Kanneliya-DediyagalaNakiyadeniya forest complex conservation management plan. IUCN-the World Conservation Union and Ministry of Lands and Forestry, Sri Lanka.
Jakeman, L.A.R. (1961). The Internal Anatomy of the Spiny Rat Mite, Echinolaelaps echidninus (Berlese). The Journal of Parasitology 47: 329-349.

Jog, M. \& M. Watve (2005). Role of parasites and commensals in shaping host behavior. Current Science 89(7): 1184-1191.

Kern, N.G. (1981). The influence of fire on populations of small mammals of the Kruger National Park. Koedoe 24: 125-157.

Kilingenberg, R.J. (1993). Understanding reptile parasites, Advanced Vivarium Systems. Lakeside, 83pp.

Krasnov, B.R., G.I. Shenbrot, I.S. Khokhlova \& R. Poulin (2005). Diversification of ecto parasite assemblages and climate: An example with fleas parasitic on small mammals. Global Ecology and Biogeography 14: 167-175.

Krasnov, B.R., M. Stanko \& S. Morand (2006). Are ectoparasite communities structured? Species co-occurrence, temporal variation and null models. Journal of Animal Ecology 75: 1330-1339.

Kurtenbach, K., H. Kampen, A. Dizij, S. Arndt, H.M. Seitz, U.E. Schaible \& M.M. Simon (1995). Infestation of rodents with larval Ixodes ricinus (Acari: Ixodidae) is an important factor in the transmission cycle of Borrelia burgdorferi s.l. in German woodlands. Journal of Medical Entomology 32(6): 807-17.

MacArthur, R.H., J.M. Diamond \& J.R. Karr (1972). Density compensation in island faunas. Ecology 53: 22-26.

Mech, L.D. (1966). The Wolves of Isle Royale. U.S. National Park Service Faunal series No. 7, Washington, 210pp.

Moore, J. (1983). Responses of an avian predator and its isopod prey to an acanthocephalan parasite. Ecology 64: 10001015.

Myers, N., R.A. Mittermeier, C.G. Mittermeier, G.A.B. da Fonseca \& J. Kent (2000). Biodiversity hotspots for conservation priorities. Nature 403: 853-858.

Phillips, W.W.A. (1980). Manual of mammals of Sri Lanka- Part II. Wildlife and Nature Protection Society of Sri Lanka, Aitken Spence \& Co., Ltd, Colombo, xi+267pp.

Pietzsch, M.E., J.M. Medlock, L. Jones, D. Avenell, J. Abbott, P. Harding \& S. Leach (2005). Distribution of Ixodes ricinus in the British Isles: Investigation of historical records. Medical and Veterinary Entomology 19: 306-314.

Scott, M.E. \& J.W. Lewis (2008). Population dynamics of helminth parasites in wild and laboratory rodents. Mammal Review 17: 95-103.

Seneviratna, P. (1965). The Ticks (Ixodoidea) of Ceylon. Part II and III. Ceylon Veterinary Journal 13: 28-54

Shinozaki, Y., T. Shiibashi, K. Yoshizawa, K. Murata, J. Kimura, S. Maruyama, Y. Hayama, H. Yoshida \& S. Nogami (2004). Ectoparasites of the Pallas squirrel, Callosciurus erythraeus, introduced to Japan. Medical and Veterinary Entamology 18: 61-63.

Soule, M. (2002). Giant Moths and doing no harm, pp.vii-ix. In: Aguirre, A.A., R.S. Ostfeld, G.M. Tabor, C. House \& M.C. Pearl (eds.). Conservation Medicine. Oxford University Press, New York, xxiv+407pp.

Spielman, A., M.L. Wilson, J.F. Levine \& J. Piesman (1985). Ecology of Ixodes Dammini-borne human Babesiosis and Lyme disease, Annual Review of Entomology 30: 439-460.

Strandtmann, R.W. \& C.J. Mitchell (1963). The Laelaptine mites of the Echinolaelaps complex from the Southwest Pacific Area (Acarina: Mesostigmata). Pacific Insects 5(3): 541-576.

Turk, F. A. (1950). Studies on Acari VI, Parasitic mites from mammalian hosts obtained from Ceylon. Parasitology 40: 63-76.

UNESCO (2008). World network of biosphere reserves. <http:// portal.unesco.org/science/en/ev.php-URL_ID $=4801 \& U R L$ DO=DO_TOPIC\&URL_SECTION=201.html $>$ On-line version dated 17 February 2009.

Verma, P.S. (2002). A manual of Practical Zoology Invertebrates. S. Chand and Company Ltd, New Delhi, $x+497 p p$. 
Waweru, C.W. \& J.E. Odanga (2004). Demographic aspects of sympatric Praomys jacksoni and P. stella in a tropical lowland forest in Kakamega, Kenya. African Journal of Ecology 42: 93-99.

Whitaker, J.O. (1988). Collecting and preserving of ecto parasites for ecological study, pp.459-747. In: Kunze, T. H. (ed.). Ecological and Behavioral Methods for the Study of Bats. Smithsonian Institute Press, Batimore, USA, 533pp.

Wijesinghe, M.R. \& M.de L. Brooke (2005). Impact of habitat disturbance on the distribution of endemic species of small mammals and birds in a tropical rain forest in Sri Lanka. Journal of Tropical Ecology 21: 661-668.

WHO (1994). Bench Aids for the Diagnosis of Intestinal Parasites. World Health Organisation, Geneva, Switzerland.
Author Details: Pamoda B. Ratnameera, as a Zoology major student carried out this study as an off shoot of her final year undergraduate research project at the University of Colombo, Sri Lanka under the guidance of Drs. Wijesinghe and Udagama Randeniya. Pamoda has several research communications presented at national and international forums.

DR. MAYURI R. WIJESINGHE is a Senior Lecturer at the Department of Zoology, University of Colombo. Her field of interest is conservation biology. Her research focuses on the ecology and behaviour of small mammals (including population dynamics, feeding, space utilization) and amphibians, two important components of Sri Lanka's biodiversity and endemism.

Dr. PreethI V. Udagama-Randeniya is a Professor at the Department of Zoology, University of Colombo. Although she is an Immuno-parasitologist, she has recorded parasites of Sri Lankan murids, bats, elephants, poultry, pigs, reptiles, amphibians, bovids and aquarium fishes. She is the recipient of several local research awards.

Author Contribution: PBR carried out the field work (captured animals and collected ectoparasites and faecal matter), preserved, prepared and microscopically examined parasite specimens, and prepared the manuscript. MRW guided the field study, obtained funds for the project and helped with the writing of the paper. PVU-R guided the identification of the ecto and intestinal parasites as well as the writing up of the manuscript, corresponded with international experts to authenticate the identity of parasites and is the corresponding author.

Acknowledgements: The following institutions are gratefully acknowledged: the National Science Foundation, Sri Lanka (grant number: RG/ 2004/ B2) and the University of Colombo for funding this project; the Forest Department and the Department of Wildlife Conservation for granting permission to carry out studies on small mammals in the forest reserves of Sri Lanka. The help of Dr. Mark Harvey, Senior Curator and Head, Department of Terrestrial Zoology, Western Australian Museum in the identification of the pseudoscorpion genus is also acknowledged. 